\title{
A Case Study of Machine Translation: Problems and Suggestions
}

\author{
Haicui Zheng ${ }^{1}$ \\ ${ }^{1}$ College of Foreign Languages, Inner Mongolia University, Huhhot, China \\ Correspondence: Haicui Zheng, College of Foreign Languages, Inner Mongolia University, Huhhot, 010070, \\ China. E-mail: zhenghaicui@yahoo.com
}

$\begin{array}{ll}\text { Received: December 16, } 2014 & \text { Accepted: January 10, } 2015 \text { Online Published: March 29, } 2015 \\ \text { doi:10.5539/ijel.v5n2p92 } & \text { URL: http://dx.doi.org/10.5539/ijel.v5n2p92 }\end{array}$

\begin{abstract}
For past decades, machine translation has made a great achievement and contribution though the process is not so smooth (Zhang, 2007). Many machine translation systems have been developed and put into use and many people especially learners turn to them when faced with a translation task. A question appears - is translation produced by these translation systems or software satisfactory? In this paper, the author applies machine translation software products developed by different companies to song lyric translation. The result is far from being satisfactory. A detailed discussion is provided to account for it. It shows that machine translation still has great space to improve. Based on this case study, the author puts forward some advice on how to make a good use of machine translation to ensure the quality of machine translation.
\end{abstract}

Keywords: machine translation, song lyrics, rank and scale theory, corpus construction, translation memory, manual evaluation

\section{Introduction}

With the development of artificial intelligence and the updating of modern technology, people's expectation and the society's demand for machine translation are becoming greater and greater. The past decades have witnessed the development of machine translation. More and more free online translation programs or systems have been developed to help people fulfill a translation task. Those whose English is not good enough to do a translation by themselves will turn to machine translation. Some of them rely on machine translation so much that they use the translation directly without making a check or correction either due to their blind trust in machine translation or because of their language incompetence. More often than not, the translations produced in this way are incorrect in many aspects, let alone being good. In this paper, the author has conducted a case study to check the feasibility and reliability of the machine translation systems prevalent among many people including college students and even English majors. The ultimate purpose is not to deny or denounce machine translation but to put forward some advice on how to make improvement in machine translation research on the one hand and how to make a good use of machine translation on the other hand.

\section{On Machine Translation}

Machine translation development can be traced backed to the early 1950s when machine translation researchers adopted the crude dictionary-based approaches which resulted in just word-for-word translation. Gradually linguistic theories were added to machine translation. According to $\mathrm{Hu}$ (2011), the machine translation methods can be classified into four kinds: 1) the linguistic approach; 2) the transfer approach; 3) the interlingual approach; 4) the knowledge-based approach. The 1990s witnessed machine translation's acceleration propelled by the development of corpus linguistics, which is mainly example-based. Such kind of machine translation presupposes the collection and storage of exiting correct translations. Many machine translation systems such as Google Translator and Bing Translator have been developed. Machine translation study has boomed, but there is great controversy as to the feasibility and capability of machine translation.

It is commonly believed that machine translation is of some help in the translation of some texts. In other words, machine translation has some limitations. "Many of the problems that machine translation faces cannot be solved at all. High-quality translation done solely by machines is not possible and machine translated texts will continue to be plagued by errors in the future, ranging from eccentric turns of phrase to grave distortions of meaning" (Madsen, 2009, p. 5). Some others also point out the existing problems. "Seen from the angle of industrialization and application, the society has an urgent demand for more applicable machine translations systems or programs. 
However, there still exists a large gap between people's demand and the result of machine translation." (Du et al., 2013, p. 2)

However, there are some scholars who have a strong belief in the capability of machine translation and they even use machine translation to try something tricky and challenging. Poetry has always been regarded as a headache or even the impossible in machine translation. However, different opinions have been voiced. Lee introduces a bilingual poetry project by a Taiwanese poet and argues that due to a loss of human agency in translation, "machine translation can produce unexpected new meanings through unpredictable routes of semantic and syntactic divergences from the source text" (Lee, 2011, p. 92). Though admitting machine translation's disadvantage of blocking comprehension, Lee holds that "machine translation plays the crucial function of bringing the reader's attention back to the target language by way of delaying comprehension." (ibid) According to Lee, the absence of translator forces the readers to think about in the target language. It may be of help in stirring readers' imagination. As far as poetry is concerned, it is probably acceptable to some degree. However, when it comes to translation proper, undoubtedly a great deal of information expressed in the source language will get lost in such kind of machine translation. Furthermore, this project has a higher demand on participants' language proficiency level. Low-proficiency readers will feel more puzzled than being forced to be creative. The project is "avant-garde" in Lee's terms (ibid).

Despite the strong arguments in machine translation's capability, machine translation still has a long way to go to win wide acclaim, especially evaluated with the transparent rendering of the full meaning of a source text in target language as the aim or criterion of translation. In view of this, this paper plans a case study to check the feasibility of machine translation.

\section{Song Lyric Translation}

Song is a special literary work. Song has a close relationship with poem, but still it is not poem due to its inseparable connection with music. A song is composed of lyrics and melody. As far as the purpose of translation is concerned, song translation can be classified into two kinds: melody-faithful version and meaning-faithful version. The former refers to the translation which makes it easy for the original song to be sung in the target language; the latter aims to explain the meaning of the original song, paying little attention to the syllable or note. Since it is impossible for most people who specialize in linguistics to put the melody along with lyrics into translation, song translation in practice is actually song lyric translation in this study, which aims to convey meaning. Due to the special literary style of song, few studies have been conducted on machine translation of song. However, unlike poetry which is sometimes hard for ordinary people to interpret, song is popular and easy to understand. It is naturally assumed that it is feasible to translate song with machine translation systems.

\section{Machine Translation of Song Lyric: A Case Study}

One song “我的根在草原” (My root's in the grassland) (The original song and my translation are put in Appendix) sung by the famous Mongolian singer Dedema is chosen to do a case study. The song lyric has been translated in this study by the 12 frequently used translation tools: Ace Translator 10.3, Lingoes Translator, Worldlingo, Google, Baidu, Youdao, Iciba, Dict. CNKI, Netat, Bing, and Hjdict. It turns out that the results are far from being satisfactory. Some are even completely wrong. Mistakes of various kinds have been found in each translation, which have been classified into several categories. The errors will first be presented and then analyzed and finally evaluated, which will appear in three different sections.

\section{1 Data Presentation}

\subsubsection{Lexicon}

琼楼玉阁 (magnificent buildings) is a Chinese phrase which actually refers to the magnificent buildings. The literal translation of the phrase is "richly decorated jade palace". The online machine translations of the phrase are listed in the following:

Qionglou Jade Court (Google), Joan LouYu pavilion (Youdao), Qionglou club (Baidu, Iciba), Joan louyuge (Bing), Joan lived all over the premises Court (Ace, Lingoes), Joan Premises Ko (Bing, Dict, Hjdict), the Kind Building Pavilion (CNKI), the fine jade building world cabinet (Netat)

奶茶手把肉 (milk tea and finger mutton), the most popular Mongolian drink and food, have got the following translations: 
tea hand meat (Google, Ace, Lingoes, Iciba, Baidu), milk tea hand through the meat (Youdao), tea is most delicious meat (Bing), tea hands the most delicious meat (CNKI, Dict, Hjdict, ), milky tea meat (Netat), tea with milk handle meat (Worldlingo)

蒙古包 (the Mongolian yurt) has been translated as "ger" by Youdao and as "Mongolia bag” by Iciba, Baidu and CNKI.

\subsubsection{Syntax}

In the sentence 走遍了山山水水, 美不过辽阔的草原 (Of the places I have gone to, the vast grassland is the most beautiful), 美不过 (an adjective + 不过) is a spoken phrase to express the superlative degree. There are similar expressions like “香不过” (which means “the most delicious”). But all the online translation tools mentioned above cannot recognize the phrase; they treat it as separate words “美” (beautiful), “不过” (but)”. The following are the translations of the sentence:

Traveled the rivers and mountains, the United States, but the vast grassland.

(Ace, Lingoes, Google)

Through the mountains, beautiful but the vast grassland

(Iciba, Baidu, CNKI, Dict, Bing, Hjdict)

Traveled massif, the United States but the vast grassland (Youdao)

Have walked through landscape US but vast grasslands (Netat)

The mountain and river beautiful, vast prairie in the prairie (Worldlingo)

Another sentence 我是父亲心爱的骏马, 永远爱恋着草原 (I'm Father's beloved steed, forever loving the grassland) has got the following translations:

My father loved horses, forever beloved prairie. (Google, Ace, Lingoes)

My father loved horses, forever love grassland. (CNKI, Dict, Hjdict)

I'm the father loved horse, always love a grassland. (Baidu, Iciba)

My father loved horses, forever enamoured of the grasslands. (Bing)

The sentence 我是母亲放飞的雄鹰, 永远俯瞰着草原 (I'm the eagle that Mother released, always overlooking the grassland) has a similar structure to the above sentence, but such similarity cannot be found in the translations.

My mother is always flying eagle, overlooking the prairie (Baidu, Iciba)

I am a mother eagle flying, never overlooking the prairie (Google, Ace, Lingoes)

I am a mother flying eagle, never overlooks the prairie (Youdao)

I'm mother flying eagle, always overlooking the Prairie (Bing, Netat)

I am flying mother Eagle, always overlooking the Prairie (CNKI, Dict, Hjdict)

I were the tiercel which the mother released for flight, forever the bird's eye view prairie (Worldlingo)

Although the machine translators happens to have some intelligence, the listed errors are not acceptable at all. Some other translations need improving or polishing. The reasons will be discussed in the following section.

\section{2 Data Analysis}

\subsubsection{Lexicon}

The mistakes listed above show that some translations are either unreadable or completely wrong. As to the phrase “琼楼玉阁” (magnificent buildings), only "the fine jade building Chinese style" produced by Worldlingo is acceptable to some degree; but a preposition is missing. It should be "the fine jade building in Chinese style". Others treat the phrase as four separate Chinese characters. So the words such as "Joan", "pavilion", "court" and "cabinet" appear in the translations. The reason for such mistakes is that the translation software has not stored 琼楼玉阁 (magnificent buildings)as a set phrase. The same happens to “美不过”, a prepositional phrase which implies a superlative. The errors show that its meaning as a phrase has not been stored in the corpus of these translation systems.

This is also true of “奶茶手把肉” (milk tea and finger mutton). In the song lyrics, there is no punctuation between “奶茶” (milk tea) and “手把肉” (finger mutton). Even with the punctuation between them “奶茶、手把 
肉”, “手把肉” (finger mutton) is in most cases translated as "hand meat” instead of "finger mutton”. So “手把 肉" (finger mutton) as a phrase cannot be found in the corpus of these translation tools.

The phrase “蒙古包” (Mongolian yurt) is translated as "Mongolian yurt” by Netat or just “yurt” by Google, Bing, Ace, Lingoes, CNKI, Dict, Worldlingo and Hjdict, which are all acceptable. But "Mongolia bag" is a wrong translation.

The phrase “山珍海味” (delicacies) is correctly translated as “delicacies" by most translations. Its literal translation "table delicacies from land and sea" (Iciba, Baidu) is acceptable and readable at least though it is redundant and the translation "a feast of fat things" by Netat is based on the meaning of the whole phrase rather than on each character though the word "fat" is not suitable. The reason for this is that the phrase has been widely used and stored in the corpus.

To conclude, to produce a good translation of words or phrases, the prerequisite is that they and their corresponding translations are stored in the corpus. Another necessary point is that the machine can identify the phrase.

\subsubsection{Syntax}

走遍了山山水水，美不过辽阔的草原 (Of the places I have gone to , the vast grassland is the most beautiful) is a sentence, but the translations are broken phrases or words, not sentences at all. This is mainly caused by the place of the subject in the original sentence and the machine translators' failure to recognize the relationship between the two clauses. In the first clause 走遍了山山水水 (I have got to many places), the subject is omitted. In the second clause 美不过辽阔的草原 (The grassland is the most beautiful), the subject is placed behind the phrase 美不过 (the most beautiful is-). Most machine translators fail to find the subject of the two clauses. Furthermore, the two clauses imply a semantic relation. The first expresses a range for the second. But the machine translators cannot figure out the implicit logic relation between the two clauses.

The sentence “我是母亲放飞的雄鹰, 永远俯瞰着草原” (I'm the eagle that Mother released, always overlooking the grassland) has the similar structure to “我是父亲心爱的骏马, 永远爱恋着草原” (I'm Father's beloved steed, forever loving the grassland), but the translations turn out to be quite different. “我” (I) has been translated in most translations of “我是父亲心爱的骏马” (I'm Father's beloved steed) but omitted in “我是母亲 放飞的雄鹰” (I'm the eagle that Mother released). All the translations about “母亲放飞的雄鹰” (the eagle that Mother released) are wrong and illogical except Worldlingo's translation "I were the tiercel which the mother released for flight, forever the bird's eye view prairie". But the tense is wrong, and “俯瞰着” (overlooking) is wrongly treated as a noun "the bird's eye view". The word "着” here indicates present tense. Again it is a grammatical problem.

These two sentences are parallel structures. In every sentence, the first clause contains a non-attributive clause which is in English put after the antecedent whereas in Chinese the modifiers are usually put before the modified. The listed translations show such kind of syntactic relationship and difference have not been identified, which result in the translation errors. The second clause's subject is omitted; the real subject should be the object of the first clause.

Another problem is the metaphors in “我是父亲心爱的骏马” (I'm Father's beloved steed) and “我是母亲放飞 的雄鹰” (I'm the eagle that Mother released). Some translations have omitted “我” (I), for “I'm Father's beloved steed" is illogical semantically. And the translation "My mother is always flying eagle" is grammatically correct and logical but the original meaning of the sentence has been changed. This shows the fact that machine translation is still incapable of recognizing and dealing with metaphors, as stated by Shuttleworth (see Li, 2014). This, however, demonstrates the artificial intelligence of the machine translation on the one hand and its rigidity on the other hand.

Furthermore, the comparison of the two sentences' translations also shows the artificial intelligence of machine translation. In the case of the first sentence, no present participle phrase is used to translate the second clause, for it is logical to say “我永远爱恋着草原” (I forever love the grassland). In other words, it is possible for the second clause to have the same subject as the first clause. In the case of the second sentence, it is illogical to say “我永远俯瞰着草原” (I always overlook the grassland). Therefore the subject of the second clause cannot be the same as the first clause and participle phrase appears in some translations. Again it reveals both the artificial intelligence of the machine translation and its rigidity.

The problem of punctuation appears not only in the sentences discussed above, but in almost all sentences. The translations produced by the online translation software are not capable of using punctuation correctly. Due to the influence of Chinese, some translations just copy comma directly from the source language rather than use 
the semicolon between the two sentences. In other words, the punctuation is not taken into consideration in translation at all. Besides sometimes tense in the two sentences are not in agreement. So grammar is still an important problem in machine translation.

\subsection{Data Evaluation}

Machine translation has made great progress but still it is not applicable in every text. Tian (2008) argues that CNKI translator is very useful in the translation of both Chinese and English science and technology texts. Shuttleworth (2014) holds that machine translation is theoretically applicable to translating all texts, but it turns out that it is mainly used in translating technical texts rather than literary texts (cited in Li, 2014). Literary translation requires good appreciation, flexibility and elegance which are impossible for machine translation. Machine translation is more suitable to be applied to non-literary translation. It has more feasibility and reliability in non-literary translation than in literary translation. Even for non-literary texts, it is impossible to completely rely on machine translation.

The natural language is flexible, creative and dynamic while the working mechanism of computer demands accuracy and strictness and cannot bear ambiguity. As Steiner states, natural language possesses complicated attributes and systems; it is the result of rationality and irrationality and it is hard to describe with strict mathematic formula (1992). Therefore it is difficult to make a perfect match between machine translation and natural language use. Different from ordinary language use, song lyric is a special kind of language, emotional and creative, short and concise in form but rich in meaning, which forms a great challenge to any translator, let alone machine translators.

\section{Suggestions}

Based on the analysis of the translation errors, the author puts forward some suggestions. For the construction of machine translation systems, integrating Halliday's rank and scale theory and building corpus are suggested. At the same time, users are advised to integrate translation memory into their translation process and to cultivate their critical ability in evaluating the result of machine translation and combine manual evaluation with machine translation.

\subsection{Integrating Rank and Scale Theory into the Machine Translation System}

In terms of working mechanism, machine translation systems can be basically divided into three categories - statistics-based, rule-based and example-based ( $\mathrm{Li}, 2014)$. The online translators employed in this case study are either statistics-based or rule-based or example-based. No matter what working mechanism is adopted in these translation systems involved in this case study, the results on the whole are not satisfactory. This means that the statistics and the examples are not large enough to produce satisfactory translations and the rules are not effective enough to guide the translation.

Since direct machine translation is infeasible in most cases, it is argued to follow Halliday's machine translation idea that translation should be preceded by lexicon analysis and grammar analysis (2007). The mistakes identified show that the machine translation may commit errors at every level of language-from word to sentence. Scale and category grammar should be combined into machine translation as a working principle. Halliday's "framework of sentence, clause, group, word and morpheme as a strict hierarchy of constituents" (2000, p. 23) is of great guidance to machine translation. Each clause should be segmented into phrases and then into words along the scale until to the smallest unit. The possible translation of the each unit will be checked in its larger unit and context. Take the phrase “琼楼玉阁” (magnificent buildings)as example. Each Chinese character will get a possible equivalent in translation such as Joan, building, jade, cabinet or pavilion. However these four free morphemes or Chinese characters form a set phrase and therefore get a special meaning. Therefore other possible translations for each character are denied when moved into a larger unit - phrase. The errors about this phrase in the case study are caused by the fact that unlike the phrase “山珍海味”(delicacies), “琼楼玉阁” (magnificent buildings) has not been stored in the corpus of these machine translators. So these online translators fail to recognize it as a phrase. The same happens to the phrases “奶茶” (milk tea) and “手把 肉" (finger mutton). Therefore it can be safely concluded that the prerequisite of a correct translation is the storage of the words or phrases in the corpus. Faced with a phrase, the machine first tries to translate each morpheme. When they are recognized as the components of a phrase, the morphemes are moved up to a larger unit along the scale. The initial translation will be modified or changed completely if the meaning of the morpheme does not remain in the phrase.

Along with lexicon analysis, grammar analysis is undergoing along the scale. Take the sentence “我是母亲放飞 的雄鹰, 永远俯瞰着草原” (I'm the eagle that Mother released, always overlooking the grassland) as example. 
Analyzed linearly, first the machine will get "I am the mother" which will be corrected when more words appear and become "I am the eagle Mother released". The second clause in this sentence should be translated as a present participle phrase, for it works as an object complement. The phrase “我是父亲心爱的骏马, 永远爱恋着 草原” (I'm Father's beloved steed, forever loving the grassland) has the almost the same structure. The two sentences contain metaphors which create difficulty for the machine translation. At present, machine translation still cannot recognize metaphor and it is hard for machine translation to be applied in literary text translation ( $\mathrm{Li}$, 2004). This accounts for the mistakes occurred in this case study from another perspective.

\subsection{Building and Updating the Corpus of the Machine Translation System}

Nowadays machine translation is developing in a pattern which combines several models and it is indispensible to build a comprehensive and substantial language corpus (Huang, 2012, p. 94). Corpus linguistics works to make machine translation more applicable and reliable. A large-scale corpus and a manageable statistic processor are both indispensable (Zhang, 2003). The most desirable way in corpus construction is to keep storing more and more actual language uses and their ideal translations. Only when the information is in store, will the machine recognize it and produce good translation. Compared with rule-governed machine translation which requires the machine to analyze the language first and then translate it, a large-scale corpus of substantial examples widely accepted and acclaimed is more likely to produce translations of high quality. Instead of artificial intelligence, the corpus machine translation requires a large and high-quality memory or storage of information. It is more applicable and manageable to enlarge a machine's memory than to improve its intelligence. It is easy to add or delete some translation examples and consequently it is easy to build and modify the corpus. One problem or challenge for corpus construction is that natural language is constantly changing, flexible and creative.

\subsection{Adopting Translation Memory into Machine Translation Process}

Translation Memory is assistant software which can be used as a strategy in machine translation. Translation Memory itself cannot do the translation from the source language to target language, but it can help both the human translator and the machine translator to remember and store the translation through repetition, thus improving translation efficiency and quality and relieving the translator's memory burden. For the professional translators, it is highly desirable and indispensable to adopt translation memory in their work.

According to Shuttleworth (2014), Translation Memory is suitable to be applied to the translation of scientific and technological texts, especially those highly repeated messages (cited in $\mathrm{Li}, 2004$ ). It does not mean Translation Memory cannot be used in the translation of literary texts, but it is not so reliable and effective. Due to the flexibility, creativity, and indeterminacy of literary language, especially the existence of prevalent metaphors, literary texts put a higher demand on translators. Literary texts are emotional and creative. Even the same word or expression may have a new meaning in different texts. Therefore, the stored translation may not work in a new text. Actually it is still the human translator who makes the judgments and final decision. As for the non-literary texts, they are usually logic and factual, and the meanings are definite. Translators have almost no chance to add their own interpretation. They have to follow the conventional translation. In this way, Translation Memory will be a great aid in the translation process.

\subsection{Combining Manual Evaluation and Proofreading with Machine Translation}

Although various programs of automatic evaluation on the quality of translation such as BLEU (Bilingual Evaluation Understudy) (Papineni, 2002, cited in Du et al., 2013) have been developed, application in practice is always a criterion to determine the quality and reliability of the translation software. At present, machine evaluation of translation still needs combining with manual evaluation (Kit \& Wong, cited in Huang, 2012, p. 65). In fact, manual checking is indispensable to ensure the quality of the translation.

This research also works as a reminder to students and other users of online translation systems that machine translation is still not reliable in all circumstances. Machine translation can only work as an aid or reference in translation. The users have to check and proofread the translation. Checking and modifying are always two necessary steps in any translation including machine translation. Cultivating a critical eye is a very important part in translation study. Translation ability and critical eye are highly correlated. The higher the translation ability is, the stronger the critical eye becomes.

Up to now, machine translation still cannot take the place of human translator. It is undesirable that machine translation is accepted blindly and completely. Whether literary texts or non-literary texts, human translator will have to exercise their initiative and intelligence to produce correct and quality translation. 


\section{Conclusion}

By doing a case study - applying twelve frequently used online translation systems to translate a popular song, this study aims to study the feasibility of machine translation. However, the result is far from being satisfactory. With mistakes, most translations have low readability, which means machine translation is hardly feasible and reliable at least in song lyric translation. The special characteristics of song lyrics are the direct reason for low-quality translation. At the same time, this case study shows that these translation software products need great improvement. It is safely concluded that despite the great development, machine translation still has a long way to go to be applicable and reliable in translating texts of all styles. Unassisted machine translation or machine translation without human involvement is still not applicable in most cases.

In spite of the existing problems, machine translation is undoubtedly in a great demand and "the errors that machine translation systems produce are not always and constantly catastrophic" (Madsen, 2009, p.102). Rank and scale theory and corpus construction are believed to be the best way to improve quality of machine translation. Translation Memory is advised to be adopted in machine translation. This research also reminds the users of translation programs that to check and to modify are always two necessary steps in translation.

\section{Acknowledgements}

This research is a part of the research project "Multimodal Discursive Construction of Mongolian Identity-Interpreting Grassland Songs" funded by the Ministry of Education of the P. R. China (No.13YJAZH139).

\section{References}

Du, J. H., Zhang, M., Zong, C. Q., \& Sun, L. (2013). Opportunities and Challenges to Machine Translation Study in China-A summary and outlook of the $8^{\text {th }}$ National Machine Translation Research Conference. Journal of Chinese Information Processing, 27(4), 1-8.

Halliday, M. A. K. (2000). An Introduction to Functional Grammar. Beijing: Foreign Language Teaching and Research Press (by arrangement with Edward Arnold).

Halliday, M. A. K. (2007). Linguistics and machine translation. In J. Webster (Ed.), Computational and Quantitative Studies. Beijing: Peking University Press.

Hu, Z. L. (Ed.). (2011). Linguistics: A Course Book (4th ed.). Beijing: Peking University Press.

Huang, S. M. (2012). The Study of Verb-Object Construction in Machine Translation (Doctoral dissertation). Central China Normal University, Wuhan, P. R. China.

Lee, T. K. (2011). The death of the translator in machine translation: A bilingual poetry project. $\begin{array}{lllll}\text { Target-International Journal of Translation } & \text { Studies, } & \text { 23(1), } & \text { 92-112. }\end{array}$ http://dx.doi.org/10.1075/target.23.1.06lee

Li, Y. J. (2014). The Present Status and Prospects of machine translation and translation technology research-an interview with Bernard Mark Shuttleworth. Chinese Science \& Technology Translator Journal, 27(1), 24-27.

Madsen, M. W. (2009). The Limits of Machine Translation (Master Thesis). Copenhagen University, Copenhagen, Denmark. Retrieved from http://www.math.ku.dk/ m01 mwm/The\%20Limits\%20of\%20Machine\%20Translation\%20(Dec.\%2023,\%2 02009).pdf

Papineni, K., Roukos, S., Ward, T. et al. (2002). BLEU: A method for automatic evaluation of machine translation. Proceedings of the $40^{\text {th }} A C L$ (pp. 311-318). Philadelphia, USA.

Steiner.G. (1992). After Babel-Aspects of Language and Translation. Oxford: Oxford University Press.

Tian, M. (2008). CNKI Translator-A great help for English and Chinese Texts of Science and Technology. Journal of Xi'an Shiyou University (Natural Science Edition), 23(5), 109-110.

Zhang, X. J. (2007). A General Review of Studies on Quantized Translation Quality Assessment. Foreign Languages Research, 104(4), 80-84.

Zhang, Z. (2003). An Evaluation of Machine Translation Theories Abroad. Journal of Tianjin Foreign Studies University, 10(3), 15-20. 


\section{Appendix}

\section{The Song “我的根在草原” (My Root's in the Grassland)}

走遍了山山水水, 美不过辽阔的草原。

听遍了四海歌声, 还是牧歌最动人。

我是父亲心爱的骏马, 永远爱恋着草原。

无论在哪里, 我的根在草原。

住遍了琼楼玉阁, 蒙古包里睡得最甜

尝遍了山珍海味, 奶茶手把肉最香。

我是母亲放飞的雄鹰, 永远俯瞰着草原

无论在哪里, 我的根在草原。

\section{My translation:}

Of the places I have gone to, the vast grassland is the most beautiful.

Of the songs I have listened to, the pastoral is the most touching.

I'm Father's beloved steed, forever loving the grassland.

No matter where I am, my root's in the grassland.

Of the magnificent buildings I have lived in, Mongolian yurt is the most comfortable.

Of various delicacies I have tasted, milk tea and finger mutton are the most delicious.

I'm the eagle that Mother released, always overlooking the grassland.

No matter where I am, my root's in the grassland.

\section{Copyrights}

Copyright for this article is retained by the author(s), with first publication rights granted to the journal.

This is an open-access article distributed under the terms and conditions of the Creative Commons Attribution license (http://creativecommons.org/licenses/by/3.0/). 